\title{
Anesthesia for transsphenoidal pituitary surgery in super morbidly obese patient
}

\author{
Sijerčić S., Dedić Simendić L., Ahmetašević Dž. \\ University Clinical Center, Dept of Anestesiology and Intensive Care, Tuzla, B\&H
}

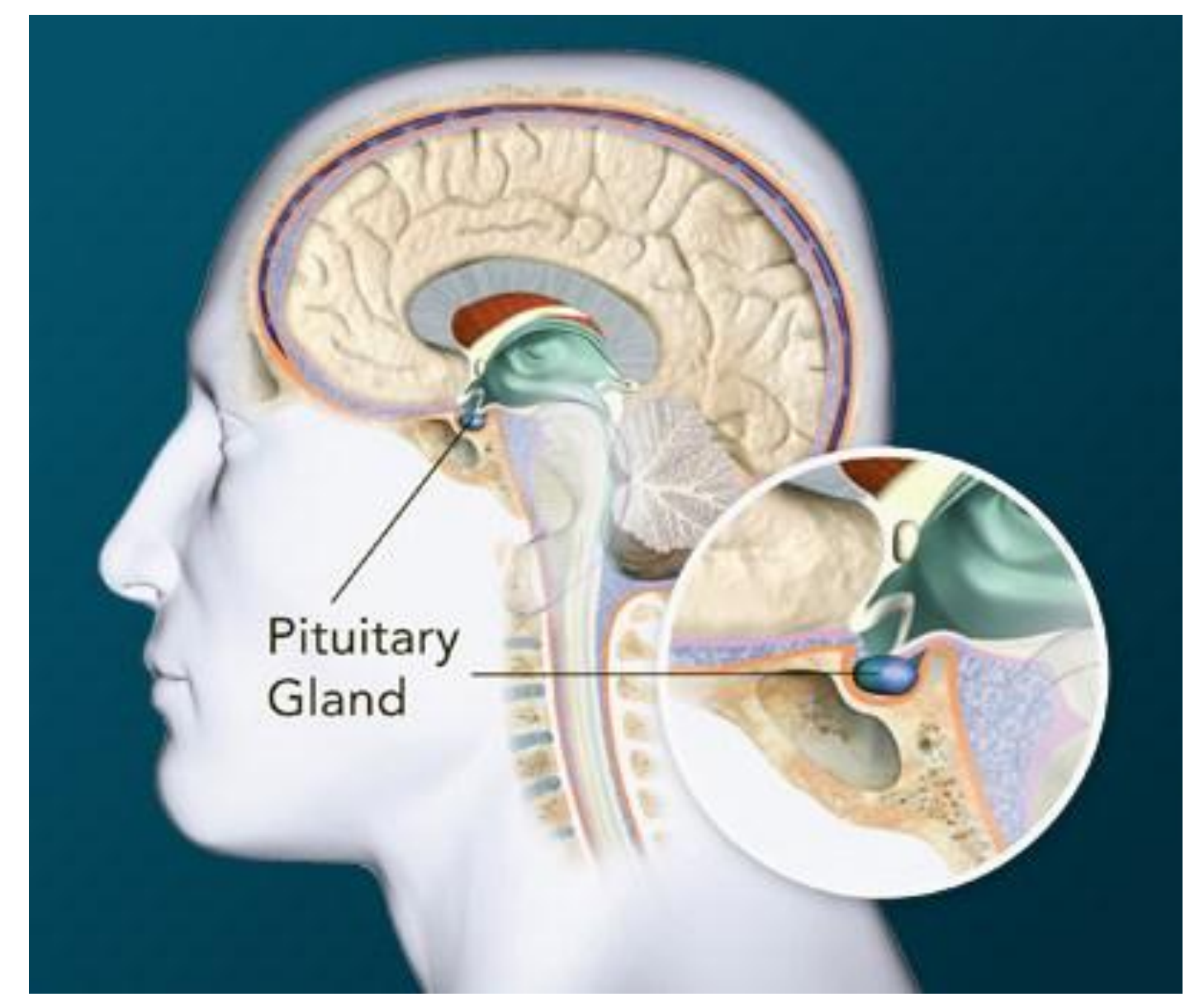

Background: Pituitary tumors are common in clinical practice, with radiologic and autopsy studies estimating that as many as one in seven people have a pituitary tumor; however, only one in 1000 are clinically symptomatic.

Case report: transsphenoidal pituitary surgery was planned for 51 years old, super obese man patient (weight $=175 \mathrm{~kg}$ and height $=187 \mathrm{~cm}$. BMI: 50,04 $\mathrm{kg} / \mathrm{m}^{2}$ ). On preoperative examination, patient had short thick neck and grade III Mallampatti class. He presented with history of Cushing's disease, hypertension, diabetes mellitus, insuffitientio renalis chronica gradus II and bronchitis chronica. He was labeled as ASA IV. All the necessary consultations have been carried out and laboratory findings were corrected. Intubation and an introduction to anesthesia have passed without complications. The patients was taken to the operating room and monitoring instituted, including an arterial line, electrocardiogram and pulse oximetry. He was preloaded with $1500 \mathrm{ml}$ of normal saline. He was then placed in sitting/semi-sitting position prior induction. Various sizes of supraglottic airway devices, endotracheal tubes and laryngoscopic blades, stylet, gum elastic bougie, fiber optic bronchoscope and kit for emergency tracheostomy were prepared before induction. Atropin $0,5 \mathrm{mg}$, fentanyl $2 \mathrm{mcg} / \mathrm{kg}, 2,5 \mathrm{mg} / \mathrm{kg}$ of propofol intravenous and leptosuccin $1,5 \mathrm{mg} / \mathrm{kg}$ was administered for anesthesia induction after three minutes of pre-oxygenation with $100 \%$ oxygen. After tracheal intubation on second attempt with an $8,0 \mathrm{~mm}$ inner diameter,, $0,5 \mathrm{mg} / \mathrm{kg}$ atracurium was administered and the patient was placed on mechanical ventilation.

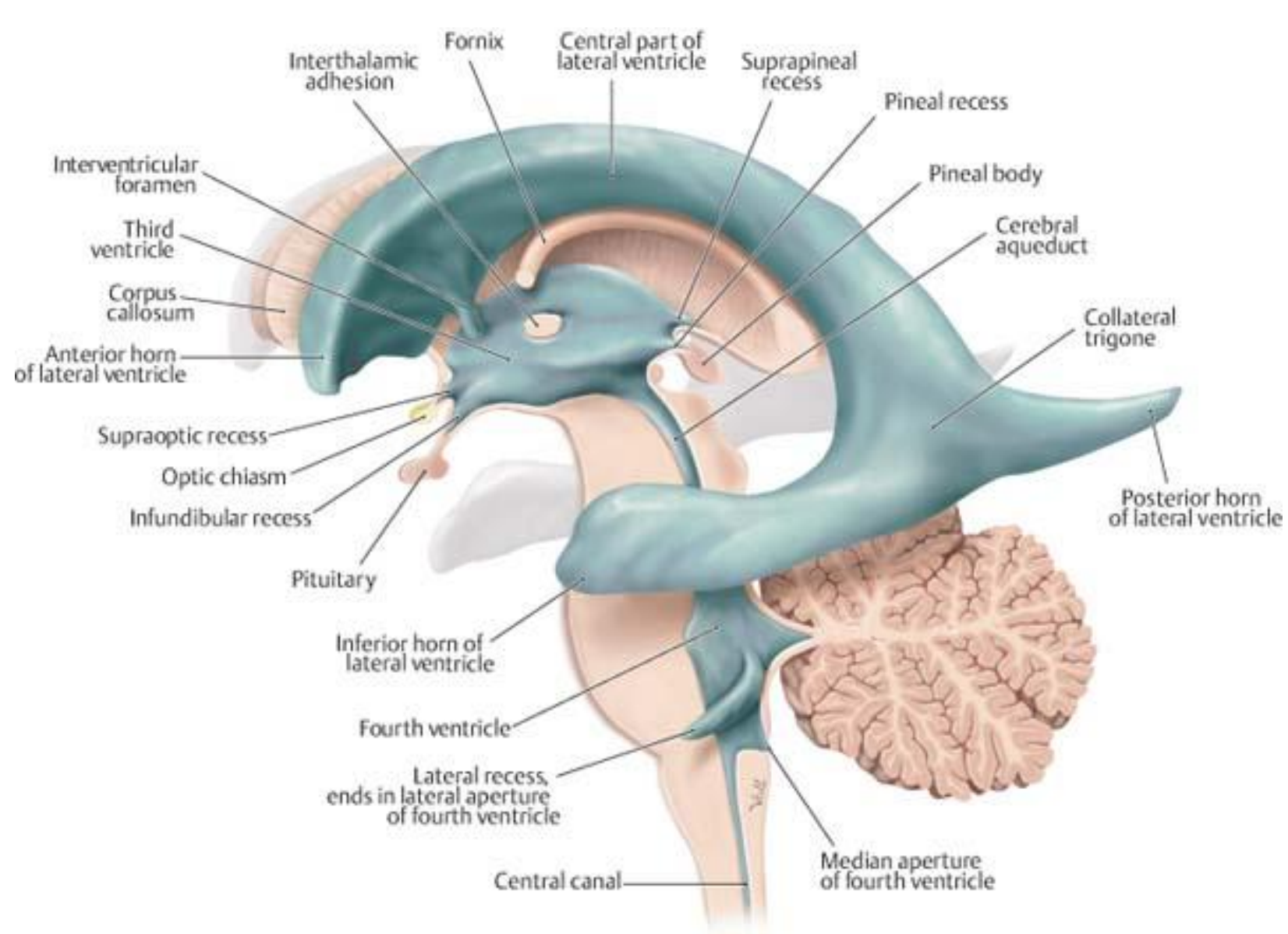

During the operation, the patient had mildly elevated blood pressure. The operation and early postoperative period have passed the orderly. The patient was transferred from the Intensive Care Unit to the fifth postoperative day at the Neurosurgery Clinic. The patient was hemodynamically stable with good diuresis. On the seventh postoperative day the condition of the patient worsened, he was reanimated, set on mechanical ventilation and given inotropic support. Myocardial infarction diagnosis (NSTEMI) was confirmed. The patient died of the ninth postoperative day.

Discussion: In this case we used short acting anesthetic agents were favored to facilitate intraoperative stability, rapid recovery and permit neurologic examination after surgery. Morbidly obese patients are at high risk with regards to aspiration and upper airway obstruction following tracheal extubation. Cushing's diseases, due to excess production of adrenocorticotropic hormone, is associated with increased risk of cardiovascular disease, hypertension, and ischemic heart disease, which is major cause of perioperative mortality.

Learning points: Anesthesia for transsphenoidal pituitary surgery requires thorough preoperative assessment of patient condition and can provide optimal surgical conditions and hemodynamic stability, while used drugs with short half life in super obese patient.

\section{References:}

-Dunn LK, Nemergut EC. Anesthesia for transsphenoidal pituitary surgery. Curr Opin Anaesthesiol. 2013;26(5):549-54.

-Domi R, Laho H. Anesthetic challenges in the obese patient. J Anesth. 2012;26:758-65.

-Sukhminderjit SB, Sukhwinder KB. Anesthesia and Intensive care implications for pituitary surgery. Indian $\mathrm{J}$ Endocrinol Metab.

2011;15(Suppl3). 